\title{
Gastric Emptying in Patients With Functional Dyspepsia and Patients With Migrain: Author's Reply
}

TO THE EDITOR: Thank you for your comments, Dr. Lee. ${ }^{1}$ Gastric scintigraphy is a noninvasive, simple to perform, and quantitative method. This study ${ }^{2}$ tried to increase the objectivity and reproducibility by examination and interpretation according to the guidelines. ${ }^{3,4} \mathrm{We}$ also tried to obtain our own data on gastric emptying (GE) times in our hospital, because we thought it was important to collect unique data in an individual institute. As Dr. Lee pointed out, ${ }^{1}$ functional dyspepsia (FD) and control group of this study showed delayed GE compared to previous studies. ${ }^{5,6}$ We already mentioned about that in the discussion. This might be because there was relatively large proportions of young female subjects enrolled in the FD and control group to match gender and age with the migraine group. Actually, females and premenopausal status showed more delayed GE than males and postmenopausal status, ${ }^{7,8}$ and a previous study found that female sex is the independent factor related to delayed GE in the patients with FD. ${ }^{9}$

Secondly, there was no significant correlation between GE and symptoms in our study as pointed out by Dr Lee. ${ }^{1}$ A tendency of delayed GE was shown in FD patients complaining postprandial fullness and early satiety. Regarding the association between GE parameters and dyspeptic symptoms in patients with FD, larger studies have shown the association of postprandial fullness and nausea with delayed GE. ${ }^{7-8}$ Our study had the limitation of a single-center study targeting a small number of patients, because we had selected the age and gender matched groups from the FD population who had undergone GE scintigraphy. However, the migraine and normal control groups were enrolled prospectively to perform gastric scintigraphy during the interictal period.

Lastly, the relationship between migraine and GE is still controversial, ${ }^{10}$ and inaccurate evaluation of gastric symptoms during interictal period was the limitation in previous studies. Therefore, we enrolled the migraine patients without gastric symptoms during interictal period in order to minimize overlaps with FD. As pointed out by Dr. Lee, ${ }^{1}$ it could be better to perform scintigraphy in the ictal period to find the correlation with nausea and vomiting that occurs in the ictal period, but it should not allowed because of an ethical reason. Gastric symptoms, including nausea and vomiting, found in the ictal period might be caused by the central and peripheral nervous mechanisms. Nausea and vomiting in migraine patients during ictal period may be known to be not related to delayed GE, but other mechanisms.

Yunju Jo

Division of Gastroenterology, Department of Internal Medicine, Eulji University School of Medicine, Eulji General Hospital, Seoul, Korea

1. Lee KJ. Gastric emptying in patients with functional dyspepsia and patients with migraine. J Neurogastroenterol Motil 2012;19:116-117.

2. Yu YH, Jo Y, Jung JY, Kim BK, Seok JW. Gastric emptying in migraine: a comparison with functional dyspepsia. J Neurogastroenterol Motil 2012;18:412-418.

3. Abell TL, Camilleri M, Donohoe K, et al. Consensus recommendations for gastric emptying scintigraphy: a joint report of the American Neurogastroenterology and Motility Society and the Society of Nuclear Medicine. Am J Gastroenterol 2008;103:753763.

4. Donohoe KJ, Maurer AH, Ziessman HA, et al Procedure guideline for adult solid-meal gastric-emptying study 3.0. J Nucl Med Technol 2009;37:196-200.

5. Quartero AO, de Wit NJ, Lodder AC, Numans ME, Smout AJ, Hoes AW. Disturbed solid-phase gastric emptying in functional dyspepsia: a meta-analysis. Dig Dis Sci 1998;43:2028-2033.

6. Tack J, Lee KJ. Pathophysiology and treatment of functional dyspepsia. J Clin Gastroenterol 2005;39(5 suppl 3):S211-S216.

7. Hutson WR, Roehrkasse RL, Wald A. Influence of gender and menopause on gastric emptying and motility. Gastroenterology 1989; 96:11-17.

8. Monés J, Carrió I, Calabuig R, et al. Influence of the menstrual cycle and of menopause on the gastric emptying rate of solids in female volunteers. Eur J Nucl Med 1993;20:600-602.

9. Stanghellini V, Tosetti C, Paternico A, et al. Risk indicators of de- 
layed gastric emptying of solids in patients with functional dyspepsia. Gastroenterology 1996;110:1036-1042.

10. Aurora S, Kori S, Barrodale P, Nelsen A, McDonald S. Gastric stasis occurs in spontaneous, visually induced, and interictal migraine. Headache 2007;47:1443-1446.

\section{Conflicts of interest: None.}

